\title{
Resultados econômicos de sistemas de produção de leite com diferentes níveis tecnológicos na região de Lavras, MG
}

\author{
[Economic results of milk production systems with different technological levels in the \\ area of Lavras, Minas Gerais, Brazil]
}

\author{
M.A. Lopes ${ }^{1}$, A.L.R. Lima $^{2}$, F.M. Carvalho ${ }^{3}$, R.P. Reis ${ }^{3}$, I.C. Santos $^{2}$, F.H. Saraiva ${ }^{2}$ \\ ${ }^{1}$ Departamento de Medicina Veterinária - Universidade Federal de Lavras \\ Caixa Postal 37 \\ 37200-000 - Lavras, MG \\ ${ }^{2}$ Acadêmico - UFLA - Bolsista de Iniciação Científica da FAPEMIG \\ ${ }^{3}$ Departamento de Administração e Economia - UFLA
}

\begin{abstract}
RESUMO
Estudou-se a rentabilidade da atividade leiteira na região de Lavras, MG, analisando a influência do nível tecnológico sobre o custo de produção do leite. Foram identificados os componentes com maior influência sobre os custos finais da atividade e calculado o ponto de equilíbrio. Os dados, provenientes de 16 sistemas de produção, representando os níveis tecnológicos baixo, médio e alto, foram coletados mensalmente, entre janeiro de 2002 e junho de 2003. Consideraram-se a margem bruta, a margem líquida e o resultado (lucro ou prejuízo) como indicadores de eficiência econômica. O nível tecnológico influenciou o custo total de produção do leite - lucratividade e rentabilidade. Os sistemas de produção com nível tecnológico baixo apresentaram o menor custo unitário. O nível tecnológico influenciou os itens componentes do custo operacional efetivo da atividade leiteira. A margem líquida positiva e a lucratividade negativa, nos três níveis tecnológicos, indicaram que os pecuaristas estarão se descapitalizando a longo prazo, mas não a médio prazo.
\end{abstract}

Palavras-chave: análise de rentabilidade, bovinocultura de leite, custo de produção, nível tecnológico, ponto de equilíbrio

\begin{abstract}
The profitability of milk activity was studied in the region of Lavras, $M G$ by analyzing the influence of the technological level on milk cost. The components with major influence on the final cost of the activity were identified and the breakeven point was calculated. Monthly data from 16 production systems representing the low, medium and high technological levels from January 2002 to June 2003 were used. The gross margin, net income and the profit or loss results for the period were used as indicators of economic efficiency. The technological level had impact on the total costs of the milk and consequently on its profitability. The low level production system showed the lowest costs. The technological level also had an impact on the operational cost of the activity. The analysis of the net income and losses observed during the period for the three technological levels suggested the farmers will capitalize in medium term but not in the long one.
\end{abstract}

Keywords: profitability analysis, milk production, cost, technological level, breakeven point

Projeto (SHA 80276/01) financiado pela FAPEMIG

Recebido para publicação em 10 de novembro de 2003

Recebido para publicação, após modificações, em 23 de julho de 2004

E-mail: malopes@ufla.br 


\section{INTRODUÇÃO}

O estudo do custo de produção é um dos assuntos mais importantes da microeconomia, pois constitui um indicativo para a escolha das linhas de produção a serem adotadas, visando apurar melhores resultados econômicos (Reis, 1999a). Para Berg e Katsman (1998), a preocupação com os custos de produção e a avaliação financeira da atividade leiteira devem ser constantes.

A necessidade de analisar economicamente a atividade leiteira é importante, pois, através dessa análise, o produtor passa a utilizar corretamente os fatores de produção (terra, trabalho e capital). A partir daí, localiza os pontos de estrangulamento para depois concentrar esforços gerenciais e/ou tecnológicos, a fim de obter sucesso na atividade (Lopes e Carvalho, 2000). Ponto crucial no custo de produção do leite é a eficiência. Uma boa forma de identificar se a atividade exercida é eficiente ou não é compará-la com a de outros produtores assemelhados (Gomes e Alves, 1999).

Pesquisadores têm-se preocupado em estimar o custo de produção e estudar a viabilidade econômica da produção de leite (Prado et al., 1995; Dignóstico..., 1996; Marques, 1999; Esteves et al., 2002), sem, entretanto, mostrarem quais fatores influenciaram o custo e sem identificarem o ponto de equilíbrio das propriedades. Dentre os fatores que podem influenciar o custo de produção, está o nível tecnológico do sistema de produção de leite. De acordo com Schiffler (1999), a produção leiteira no mundo tem se elevado via inovação tecnológica. Madalena (2001) salientou que a pecuária leiteira rentável deve se basear em diversos componentes, dentre os quais cita o uso de instalações, máquinas e equipamentos simples, quando justificados economicamente. Holanda Jr. e Madalena (1998) concluíram que propriedades menos tecnificadas, embora tenham apresentado menor produtividade, apresentaram custos mais baixos e foram mais rentáveis.

O objetivo desta pesquisa foi estudar a rentabilidade da atividade leiteira de sistemas de produção de leite na região de Lavras/MG, segundo o nível tecnológico. Pretendeu-se, ainda, identificar os componentes que exerceram maior influência sobre os custos finais da atividade e identificar o ponto de equilíbrio.

\section{MATERIAL E MÉTODOS}

Os dados foram provenientes de 16 sistemas de produção de leite localizados na região de Lavras, sul do estado de Minas Gerais, coletados entre janeiro de 2002 e junho de 2003.

Os dados foram cadastrados no software Custo Bovino Leite ${ }^{\circledR}$ (Lopes et al., 2002), que contempla as duas estruturas de custo de produção: custos totais de produção, que envolvem os custos fixos e variáveis, utilizados por Reis (1999b), e custo operacional, proposto por Matsunaga et al. (1976). Os itens que compõem o custo operacional efetivo de produção do leite foram divididos em: mão-deobra, alimentação, sanidade, reprodução, ordenha, impostos, energia e combustível e despesas diversas (Lopes e Lopes, 1999).

Para evitar duplicidade de lançamento de despesas, a análise não considerou a depreciação de matrizes, uma vez que o sistema avalia o custo de produção da atividade como um todo, com os custos de cria e recria de fêmeas de reposição, e os de manutenção de vacas secas.

Utilizando-se um questionário e uma caderneta de campo, foi realizado o inventário completo dos bens, apurando-se o valor e a vida útil de cada ativo, posteriormente agrupados em: benfeitorias, máquinas, veículos, equipamentos e implementos, ferramentas e rebanho. Quando o pecuarista não dispunha de informações referentes ao valor e à data de aquisição para as estimativas do valor atual e da vida útil restante, os bens foram analisados em função do estado de conservação, enquadrados em: ótimo, bom, regular ou ruim, isto é, foram estimados em 100, 75,50 e $25 \%$, respectivamente, dos valores de mercado dos bens novos. Em função da área, do estado de conservação e do padrão de acabamento, foi estimado um valor por $\mathrm{m}^{2}$ de construção.

Para estimar a influência do nível tecnológico sobre o custo de produção do leite, os 16 sistemas de produção foram enquadrados em níveis tecnológicos: baixo, médio ou alto, sendo os grupos compostos por 4, 9 e 3 sistemas de produção, respectivamente. $\mathrm{O}$ enquadramento baseou-se nas informações obtidas no inventário, na sofisticação de equipamentos, como, por exemplo, modelo do tanque de resfriamento de leite, e nas observações realizadas durante as 
visitas mensais. No nível tecnológico alto, foram enquadrados os sistemas de produção que possuíam ordenhadeira mecânica do tipo leite canalizado, altos investimentos em máquinas e implementos agrícolas e instalações sofisticadas. Nesse nível, o grupo genético dos animais foi igual ou superior a 15/16 de fração da raça Holandesa. No nível tecnológico baixo, foram enquadrados os sistemas de produção que não possuíam máquinas e implementos agrícolas e ordenhadeira mecânica e com pequeno investimento em instalações. $\mathrm{O}$ rebanho era composto de animais mestiços ou de grupo genético não definido. No nível tecnológico médio, foram enquadrados os sistemas de produção intermediários.

Os índices produtivos e econômicos foram comparados por meio de análises descritivas, utilizando o aplicativo MS Excel ${ }^{\circledR}$, e agrupados em tabelas.

\section{RESULTADOS E DISCUSSÃO}

$\mathrm{Na}$ Tab. 1 apresenta-se um resumo dos recursos disponíveis nos 16 sistemas de produção. Na Tab. 2 há um resumo da análise de rentabilidade da atividade leiteira nos sistemas de produção estudados. $\mathrm{O}$ desvio-padrão indica que as fazendas foram diferentes entre si.

A receita total correspondeu à soma dos valores apurados com a venda de leite $(84,9 \pm 3,6 \%$; $89,4 \pm 15,5 \%$ e $93,3 \pm 7,3 \%)$, de animais $(13,8 \pm 3,0 \% ; \quad 10,0 \pm 15,1 \%$ e $6,7 \pm 7,3 \%)$ e de subprodutos $(0,8 \pm 1,6 \% ; 0,7 \pm 1,2 \%$ e 0,0$)$, nos níveis tecnológicos baixo, médio e alto, respectivamente. Essas diferenças podem ser atribuídas à quantidade de leite produzida, isto é, quanto maior o nível tecnológico maior foi a produção de leite. A receita subprodutos referese à venda de esterco, e 75\%,66,6\% e 100\% das propriedades, na ordem de citação acima, não o comercializaram. Nestas, parte do esterco foi utilizado como adubo orgânico em capineiras do sistema de produção. Sua utilização na propriedade significa redução da receita e, conseqüentemente, redução nas despesas de manutenção das capineiras.

A produtividade de leite por ha/ano (Tab. 3) é menor do que as citadas por Gomes (1997), Schiffler et al. (1999) e Lopes et al. (2001). Esses índices, aliados ao número de matrizes por hectare, indicam capacidade ociosa de utilização da área, principalmente nos sistemas de produção de nível tecnológico médio.

Em dois sistemas de produção com baixo nível tecnológico, o custo variável por litro de leite foi superior ao preço de venda, não permitindo que se atingisse o ponto de equilíbrio. Neles, a produção média diária foi de $72,33 \mathrm{~kg}$, e o ponto de equilíbrio deveria ser de $79,76 \mathrm{~kg}$ de leite por dia (Tab. 3). Dos nove sistemas de produção com nível tecnológico médio, em três o custo variável do litro de leite foi superior ao preço de venda, o que também não permitiu que se atingisse $o$ ponto de equilíbrio. Nestes, a produção média diária foi de $268,91 \mathrm{~kg}$. Em dois sistemas de produção de alto nível tecnológico, o custo variável por litro de leite foi inferior ao preço de venda, e o ponto de equilíbrio foi de $1.219,75 \mathrm{~kg} /$ dia. Neles, a produção média diária foi de $465,72 \mathrm{~kg}$. Nos três grupos, os índices evidenciam que esforços gerenciais $\mathrm{e}$ tecnológicos devem ser feitos com o objetivo de aumentar a média diária de produção, sem, contudo, aumentar o custo variável por litro de leite. Uma alternativa é aumentar a eficiência produtiva, ou seja, a produtividade por matriz, otimizando as despesas com mão-de-obra, medicamentos, inseminação artificial, impostos fixos, energia e despesas diversas.

$\mathrm{O}$ preço médio recebido por $\mathrm{kg} / \mathrm{leite}$ foi de $\mathrm{R} \$ 0,38, \mathrm{R} \$ 0,39$ e $\mathrm{R} \$ 0,42$, para os sistemas de produção com baixo, médio e alto nível tecnológico, respectivamente. Os sistemas de produção com alto nível tecnológico foram os de maior produção, evidenciando melhor remuneração por maiores quantidades. No período de estudo, o preço médio praticado no estado de Minas Gerais foi de R\$0,40 (Preço..., 2003).

O custo operacional total (COT) permitiu que se fizesse reserva para reposição dos bens (depreciação) e remuneração da mão-de-obra familiar.

O maior percentual do índice de depreciação nos sistemas de produção de médio nível tecnológico em relação ao baixo (Tab. 3) deve-se ao fato de que quanto maior o investimento em máquinas, equipamentos e benfeitorias, maior será o "peso" do item depreciação. Ainda, espera-se que a depreciação tenha maior "peso" nos sistemas de produção com maior nível tecnológico, pois o 
valor do patrimônio, sem considerar a terra, é, nesses sistemas, bem maior. Os produtores enquadrados no nível tecnológico mais alto foram os que obtiveram as maiores produções, mostrando que a otimização da estrutura física da empresa pelo aumento da escala de produção, até determinados níveis, reduz o custo operacional total por unidade (Tab. 4). Nesses sistemas, observou-se a maior eficiência produtiva $(12,57 \mathrm{~kg} / \mathrm{vaca} / \mathrm{dia})$. Lopes et al. (2001), ao estudarem um sistema de produção de médio porte $(240 \mathrm{~kg}$ de leite/dia) com alto nível tecnológico, constataram que a depreciação representou 17,3\% do COT. Embora na literatura não existam informações sobre o valor ideal para esse indicador técnico, pode-se dizer que a eficiência de utilização dos bens patrimoniais foi superior à do sistema estudado pelos autores citados.

Os itens que compõem o custo operacional efetivo (COE) de produção do leite (Tab. 2) foram responsáveis pelos percentuais encontrados na Tab. 5.

Tabela 1. Recursos disponíveis em 16 sistemas de produção de leite, agrupados em função do nível tecnológico

\begin{tabular}{lcccccccc}
\hline \multirow{2}{*}{ Descrição } & \multicolumn{2}{c}{ Baixo } & & \multicolumn{2}{c}{ Médio } & & \multicolumn{2}{c}{ Alto } \\
\cline { 2 - 3 } & Média & DP & & Média & DP & & Média & DP \\
\hline Valor do patrimônio sem a terra (R\$) & $32.197,96$ & $16.360,43$ & $76.566,82$ & $33.591,57$ & & $117.331,09$ & $25.516,93$ \\
Valor do patrimônio em terra (R\$) & $46.873,00$ & $19.740,33$ & & $166.004,67$ & $140.468,79$ & & $319.833,33$ & $67.082,66$ \\
Área (ha) & 13,75 & 6,75 & & 65,78 & 42,83 & & 114,33 & 44,29 \\
Número de animais em lactação / dia & 14,00 & 6,73 & & 24,56 & 8,50 & & 78,33 & 62,52 \\
Mão-de-obra (serviços / dia) & 1,00 & 0,00 & & 1,83 & 0,79 & & 4,00 & 2,00 \\
\hline
\end{tabular}

$\mathrm{DP}=$ Desvio-padrão.

Tabela 2. Resumo da análise de rentabilidade da atividade leiteira de 16 sistemas de produção, agrupados em função do nível tecnológico, em R\$

\begin{tabular}{|c|c|c|c|c|c|c|}
\hline \multirow{2}{*}{ Descrição } & \multicolumn{2}{|c|}{ Baixo } & \multicolumn{2}{|c|}{ Médio } & \multicolumn{2}{|c|}{ Alto } \\
\hline & Média & DP & Média & DP & Média & DP \\
\hline Receitas & $29.386,32$ & $16.732,01$ & $53.589,95$ & $21.617,51$ & $254.726,52$ & $235.706,53$ \\
\hline Leite $(\mathrm{R} \$)$ & $24.948,10$ & $13.530,00$ & $47.911,78$ & $23.169,59$ & $237.587,11$ & $231.122,32$ \\
\hline Animais (R\$) & $4.047,18$ & $2.566,31$ & $5.351,45$ & $3.215,06$ & $17.139,40$ & $15.500,87$ \\
\hline Subprodutos (R\$) & 389,77 & 779,55 & 326,72 & 682,45 & 0,00 & 0,00 \\
\hline Custo operacional total & $27.315,15$ & $20.334,49$ & $52.486,81$ & $23.016,70$ & $242.114,84$ & $254.369,42$ \\
\hline Custo operacional efetivo & $20.193,77$ & $17.984,87$ & $40.416,04$ & $20.004,92$ & $228.126,27$ & $253.647,63$ \\
\hline Custo com depreciação & $3.206,38$ & $2.108,07$ & $8.310,77$ & $4.956,39$ & $12.788,56$ & $5.461,61$ \\
\hline Mão-de-obra familiar & $3.915,00$ & 630,00 & $3.760,00$ & $2.256,19$ & $1.200,00$ & $2.078,46$ \\
\hline Custo total: & $32.877,90$ & $23.433,79$ & $73.370,26$ & $30.902,60$ & $277.612,60$ & $261.016,87$ \\
\hline Custos fixos & $8.497,33$ & $5.002,57$ & $28.609,79$ & $15.15 \mathrm{C}$ & $43.792,40$ & $8.348,53$ \\
\hline cão da terra & $2.348,25$ & 1.302 & $13.517,80$ & 8.769 & $21.056,95$ & $1.892,48$ \\
\hline Remı & $2.772,12$ & 1.654 & $6.448,36$ & 2.88 & $9.655,44$ & $3.781,74$ \\
\hline Remı & 0,00 & 0,00 & 0,00 & 0,00 & 0,00 & 0,00 \\
\hline Impo & 170,59 & 123 & & 142 & 291,45 & 268,30 \\
\hline Dep & 3.200 & 2.108 & 77 & 4.9 & 12.7 & 5.46 \\
\hline Custo & & 18.4 & 44. & 20. & 233.8 & 257.3 \\
\hline Custo & 20.02 & 17.88 & 18 & 19.9 & 227.8 & $253.391,77$ \\
\hline Mão- & $3.915,00$ & 630 & 3.7 & 2.25 & 1.20 & $2.078,46$ \\
\hline Rem & 442 & 357 & & 44 & 4.78 & $5.357,21$ \\
\hline Margem & $9.192,54$ & 7.88 & 13.1 & 10.6 & 26.60 & 40.68 \\
\hline Marge & $2.071,16$ & 9.50 & 14 & 10.91 & $12.611,68$ & $38.106,03$ \\
\hline Resultad & $(3.491,59)$ & $11.982,94$ & $(19.780,31)$ & $16.660,72$ & $(22.886,08)$ & $40.092,22$ \\
\hline Margem & 0,18 & 0,15 & 0,13 & 0,12 & 0,09 & 0,09 \\
\hline Margem lí & 0,05 & 0,16 & 0,01 & 0,09 & 0,04 & 0,08 \\
\hline Resultado (lucro ou prejuízo)/kg leite & $(0,04)$ & 0,19 & $(0,18)$ & 0,17 & $(0,08)$ & 0,14 \\
\hline Lucratividade $(\%)$ & $-10,51 \%$ & $41,94 \%$ & $-39,85 \%$ & $35,63 \%$ & $-19,39 \%$ & $33,24 \%$ \\
\hline Rentabilidade (\%) & $1,72 \%$ & $7,65 \%$ & $-3,40 \%$ & $8,19 \%$ & $-3,12 \%$ & $5,34 \%$ \\
\hline Quantidade de leite $(\mathrm{kg})$ & $65.767,46$ & $35.749,88$ & $122.867,33$ & $59.451,16$ & $558.302,00$ & $542.249,46$ \\
\hline
\end{tabular}


Tabela 3. Índices técnicos e gerenciais em 16 sistemas de produção de leite, agrupados em função do nível tecnológico

\begin{tabular}{|c|c|c|c|c|c|c|}
\hline \multirow{2}{*}{ Item } & \multicolumn{2}{|c|}{ Baixo } & \multicolumn{2}{|c|}{ Médio } & \multicolumn{2}{|c|}{ Alto } \\
\hline & Média & DP & Média & DP & Média & DP \\
\hline Depreciação/COT (\%) & 12,81 & 3,05 & 16,67 & 7,21 & 9,55 & 6,09 \\
\hline COE/COT (\%) & 64,22 & 17,97 & 74,17 & 11,20 & 87,95 & 9,53 \\
\hline Mão-de-obra familiar/COT (\%) & 22,96 & 15,62 & 9,16 & 8,42 & 2,50 & 4,33 \\
\hline Custo fixo/custo total (\%) & 28,55 & 6,22 & 38,87 & 12,07 & 26,97 & 18,64 \\
\hline Custo variável/custo total (\%) & 71,45 & 6,22 & 61,13 & 12,07 & 73,03 & 18,64 \\
\hline Depreciação/custo total (\%) & 10,29 & 1,84 & 11,58 & 4,23 & 6,97 & 3,92 \\
\hline Produtividade animal/dia (kg de leite) & 8,30 & 0,80 & 8,74 & 2,65 & 12,57 & 2,97 \\
\hline Produção diária (kg de leite) & 120,01 & 65,24 & 224,21 & 108,49 & $1.054,41$ & 947,02 \\
\hline Produção de leite por hectare/ano $(\mathrm{kg})$ & $3.192,29$ & 639,94 & $1.831,02$ & $1.289,34$ & $4.195,53$ & $4.605,75$ \\
\hline Número de vacas em lactação/ha (matrizes) & 1,06 & 0,20 & 0,68 & 0,68 & 0,85 & 0,84 \\
\hline Produção de leite/mão-de-obra (kg/serviço) & 120,01 & 65,24 & 125,00 & 52,07 & 231,29 & 106,64 \\
\hline Relação vaca/homem & 14,00 & 6,73 & 14,26 & 3,79 & 18,33 & 6,29 \\
\hline Ponto de equilíbrio ( $\mathrm{kg}$ de leite/dia) & 79,76 & & 3706,25 & & 1219,75 & \\
\hline
\end{tabular}

$\mathrm{DP}=$ desvio-padrão; $\mathrm{COT}=$ custo operacional total; $\mathrm{COE}=$ custo operacional efetivo.

Tabela 4. Custos médios de produção, por quilograma de leite, de 16 sistemas de produção de leite, agrupados em função do nível tecnológico, em R\$

\begin{tabular}{|c|c|c|c|c|c|c|}
\hline \multirow{2}{*}{ Item } & \multicolumn{2}{|c|}{ Baixo } & \multicolumn{2}{|c|}{ Médio } & \multicolumn{2}{|c|}{ Alto } \\
\hline & Média & DP & Média & DP & Média & DP \\
\hline Custo operacional total & 0,39 & 0,15 & 0,46 & 0,11 & 0,41 & 0,04 \\
\hline Custo operacional efetivo & 0,26 & 0,15 & 0,34 & 0,08 & 0,37 & 0,07 \\
\hline Custo total & 0,49 & 0,17 & 0,65 & 0,18 & 0,53 & 0,10 \\
\hline Custo fixo & 0,14 & 0,06 & 0,26 & 0,15 & 0,15 & 0,13 \\
\hline Custo variável & 0,35 & 0,13 & 0,39 & 0,09 & 0,38 & 0,06 \\
\hline Preço médio de venda do leite & 0,38 & 0,01 & 0,39 & 0,02 & 0,42 & 0,02 \\
\hline
\end{tabular}

$\mathrm{DP}=$ Desvio-padrão.

Tabela 5. Custo operacional efetivo de 16 sistemas de produção de leite, agrupados em função do nível tecnológico

\begin{tabular}{|c|c|c|c|c|c|c|}
\hline \multirow{2}{*}{ Item } & \multicolumn{2}{|c|}{ Baixo } & \multicolumn{2}{|c|}{ Médio } & \multicolumn{2}{|c|}{ Alto } \\
\hline & Média (\%) & DP & Média (\%) & DP & Média (\%) & DP \\
\hline Mão-de-obra & 5,48 & 5,18 & 16,65 & 11,29 & 14,07 & 4,60 \\
\hline Alimentação & 64,76 & 5,77 & 55,63 & 13,09 & 66,49 & 10,79 \\
\hline Sanidade & 4,68 & 2,36 & 3,77 & 1,60 & 2,47 & 1,06 \\
\hline Inseminação artificial & 0,00 & 0,00 & 0,15 & 0,44 & 0,74 & 0,67 \\
\hline Ordenha & 0,00 & 0,00 & 0,67 & 0,79 & 2,69 & 0,66 \\
\hline Impostos (ITR e IPVA) & 0,87 & 0,57 & 1,02 & 0,78 & 0,22 & 0,20 \\
\hline Energia & 8,08 & 3,72 & 12,65 & 5,88 & 5,45 & 2,32 \\
\hline Despesas diversas & 16,14 & 8,93 & 9,45 & 4,72 & 7,86 & 2,96 \\
\hline
\end{tabular}

$\mathrm{DP}=$ Desvio-padrão

Na mão-de-obra, a diferença entre os níveis médio e alto pode ser explicada pela maior adoção de tecnologias, incluindo o uso de ordenhadeira mecânica, que otimizou em 22,2\% o item mão-de-obra, evidenciada pela relação vaca:homem de 14,26:1 e 18,33:1, respectivamente (Tab. 3). O valor de 5,5\% obtido no sistema de produção com baixo nível tecnológico foi muito pequeno. Tal valor pode ser explicado pelo fato de $75 \%$ dessas propriedades adotarem a mão-de-obra familiar, e apenas $50 \%$ delas, eventualmente, contratarem pessoal. Assim, diminuiu-se o desembolso com mão-de-obra pela redução na contratação de pessoal. Essa evidência é corroborada pela baixa relação vaca:homem, de 14,0:1. Se a relação é baixa, a demanda por pessoal é maior, e o percentual de despesas referentes à mão-de-obra 
tende a aumentar. Lopes et al. (2001) verificaram que a rentabilidade foi altamente insatisfatória ao encontrar a relação vaca:homem de 7:1. Nesse caso, a mão-de-obra foi responsável por $25,8 \%$ do total das despesas operacionais efetivas. Jarret (1997) sugeriu a relação vaca:homem de 66:1 e 111:1 para sistemas de produção com 300 e 1000 vacas, respectivamente.

A produção diária de leite por mão-de-obra permanente para sistemas de produção com baixo e médio nível tecnológico (Tab. 3) está muito aquém da obtida por Schiffer et al. (1999), $246,12 \mathrm{~kg}$. Esses índices, quando comparados com o do sistema com alto nível tecnológico, $231,29 \mathrm{~kg}$, foram 92,7 e $85,0 \%$ menores, confirmando que "a tecnologia facilita a vida e aumenta a produtividade" (Lopes, 1997).

O maior percentual do item alimentação no grupo com alto nível tecnológico deve-se ao fato de que, em dois dos três sistemas de produção analisados, as vacas foram totalmente confinadas durante todo o período. $\mathrm{O}$ alto percentual nos sistemas de baixo nível tecnológico pode ser explicado pelos baixos percentuais de mão-deobra, inseminação artificial e ordenha. Todos os sistemas de produção utilizaram suplementação com concentrado durante todo $\mathrm{o}$ ano $\mathrm{e}$ suplementação com volumoso e concentrado na seca.

As despesas com medicamentos (sanidade) foram mais altas nos sistemas de produção com baixo nível tecnológico.

As despesas com inseminação artificial foram pequenas nos sistemas de nível tecnológico médio, pois apenas uma das nove propriedades estudadas adotou essa tecnologia, o que pode ser deduzido pelo alto desvio-padrão desse item. A inseminação artificial não foi adotada por um dos três sistemas de produção com alto nível tecnológico e por nenhum dos sistemas de produção com baixo nível tecnológico.

As despesas com ordenha foram maiores com o aumento do nível tecnológico dos sistemas, representados principalmente por gastos com a ordenha mecânica. A diferença se explica pelo fato de quatro dos nove sistemas de produção do grupo de média tecnologia não usar material de limpeza, papel toalha, desinfetantes e soluções pré e pós-imersão. Os resultados evidenciam pouca preocupação com a obtenção higiênica do leite.

Impostos considerados fixos como o ITR e o IPVA representaram muito pouco no percentual de despesas operacionais efetivas.

O item energia incluiu as despesas com energia elétrica e combustíveis. Em despesas diversas, consideraram-se as despesas com frete do leite, taxas e impostos variáveis em função da produção e as despesas com manutenção de benfeitorias, máquinas e equipamentos. Os valores estão bem abaixo dos mencionados por Lopes et al. (2001) e Almeida Júnior et al. (2002).

Pela Tab. 2 observa-se que o valor das receitas menos os custos variáveis foram positivos e que o valor das receitas menos o custo total indicaram que os custos variáveis foram pagos, a reserva referente à depreciação pôde ser realizada, mas o capital investido em bens e terra não foi totalmente remunerado. Os resultados mostram que os sistemas de produção, em média, estão se descapitalizando ao longo do tempo.

Os custos fixos não representaram desembolso, com exceção dos impostos, mas indicaram o que a atividade deveria remunerar para ser competitiva, ao ser comparada com outras atividades econômicas, e não descapitalizar o pecuarista ao longo dos anos. Os custos fixos representaram 28,$6 ; 38,9$ e $27,0 \%$ do custo total nos sistemas de produção com baixo, médio e alto nível tecnológico (Tab. 3). Eles são altos quando comparados aos $16,1 \%$ encontrados por Almeida Júnior et al. (2002) e indicaram que os investimentos foram dimensionados para produção de leite acima da obtida.

As diferenças nos custos variáveis entre os três níveis tecnológicos podem ser explicadas pela quantidade de leite produzida.

Os indicadores de eficiência econômica, margens bruta e líquida, foram positivos, evidenciando que a atividade leiteira tem condições de sobreviver no curto e médio prazos. Quando analisada pelo indicador de eficiência econômica "resultado", a atividade leiteira não conseguiu remunerar o capital nos três níveis tecnológicos. Nos sistemas com nível tecnológico baixo, não se observou margem bruta negativa, pois o que 
foi apurado com a venda de leite, animais e esterco foi suficiente para cobrir as despesas operacionais efetivas. Em dois sistemas, a margem líquida foi positiva, mas a receita foi suficiente apenas para cobrir as despesas operacionais e não para fazer as reservas necessárias para substituição dos bens ao término de sua vida útil. Nesse caso, os produtores estavam se descapitalizando a cada ciclo produtivo. Em um sistema, o resultado foi positivo e cobriu todas as despesas, assim, o empresário conseguiu remunerar o capital em níveis acima da caderneta de poupança e não se descapitalizou.

Em apenas um dos nove sistemas de produção com nível tecnológico médio, a margem bruta foi negativa, isto é, a venda de leite, animais e esterco não foi suficiente para cobrir as despesas operacionais efetivas. Em três, a margem líquida foi negativa, mas a receita foi suficiente para cobrir as despesas operacionais efetivas. Contudo, ela não foi suficiente para fazer as reservas necessárias para substituição dos bens ao término de sua vida útil. Novamente, a descapitalização do produtor foi evidente.

Dos três sistemas de produção com nível tecnológico alto, um obteve margem bruta negativa, evidenciando que o que foi apurado com a venda de leite, animais e esterco não foi suficiente para cobrir as despesas operacionais efetivas. Em um, a margem líquida foi positiva, isto é, a receita foi suficiente para cobrir as despesas e fazer a reserva necessária para substituição dos bens ao término de sua vida útil. Dois resultados foram negativos, indicando descapitalização. A venda de animais representou $16,0,3,3$ e $3,4 \%$ da receita nas três propriedades estudadas. Isto fez a diferença nos resultados. Almeida Junior et al. (2002) constataram que a venda de animais excedentes contribuiu decisivamente para o melhor desempenho econômico na atividade leiteira.

A lucratividade de $-10,51 ;-39,85$ e $-19,39 \%$ significou que, para cada $\mathrm{R} \$ 100,00$ investidos, houve perda de $\mathrm{R} \$ 10,51$; $\mathrm{R} \$ 39,85$ e $\mathrm{R} \$ 19,39$, enquanto que rentabilidade foi de 1,$72 ;-3,40$ e $3,12 \%$ nos sistemas de produção com níveis tecnológicos baixo, médio e alto, respectivamente. Menor rentabilidade dos sistemas de produção mais tecnificados foi relatada por Holanda Jr. e Madalena (1998) e Madalena (2001).

A Tab. 4 apresenta os custos médio de produção por quilograma de leite. Os valores médios de venda foram suficientes para cobrir as despesas operacionais efetivas ou os custos variáveis, mas não foram suficientes para cobrir os custos totais.

A Tab. 6 apresenta os custos médios de produção por quilograma de "leite virtual". O termo "leite virtual" (Lopes e Lopes, 1999) significa a quantidade de leite, em $\mathrm{kg}$, resultante da conversão dos valores apurados com a venda de animais e esterco. Esse valor pode ser tomado como referência para o produtor avaliar se a atividade leiteira, principalmente a cria e recria de animais, é viável economicamente. Neste caso, os valores médios de venda foram suficientes para cobrir as despesas operacionais totais. As despesas referentes ao custo total não foram totalmente cobertas, evidenciando que parte do custo fixo, principalmente a remuneração do capital investido, não foi coberta.

Tabela 6. Custos médios de produção, por quilograma de leite virtual, de 16 sistemas de produção, agrupados em função do nível tecnológico, em R\$

\begin{tabular}{|c|c|c|c|c|c|c|}
\hline \multirow{2}{*}{ Descrição } & Baixo & & Médio & & Alto & \\
\hline & Média & DP & Média & DP & Média & DP \\
\hline Custo operacional total & 0,28 & 0,09 & 0,35 & 0,09 & 0,41 & 0,08 \\
\hline Custo operacional efetivo & 0,23 & 0,09 & 0,29 & 0,08 & 0,35 & 0,08 \\
\hline Custo total & 0,36 & 0,09 & 0,51 & 0,16 & 0,52 & 0,16 \\
\hline Custo fixo & 0,13 & 0,04 & 0,22 & 0,12 & 0,17 & 0,16 \\
\hline Custo variável & 0,24 & 0,09 & 0,29 & 0,08 & 0,36 & 0,08 \\
\hline Preço médio de venda do leite & 0,38 & 0,01 & 0,39 & 0,02 & 0,42 & 0,02 \\
\hline
\end{tabular}

$\mathrm{DP}=$ Desvio-padrão. 
Dentro do preconizado por Lopes (2003), considerando o custo operacional total do leite de $\mathrm{R} \$ 0,39$ (Tab. 4) e o valor de venda de $\mathrm{R} \$ 0,38$ no grupo nível tecnológico baixo, a atividade leiteira não foi viável economicamente, pois o produtor teve prejuízo de $\mathrm{R} \$ 0,01$ por $\mathrm{kg}$ de leite. No custo operacional de $\mathrm{R} \$ 0,39 / \mathrm{kg}$, foram computadas todas as despesas, inclusive a criação de bezerras e demais categorias animais. Contudo, nesse período, os produtores venderam alguns animais. O software Custo Bovino Leite, utilizado no processamento eletrônico dos dados desta pesquisa, realizou a conversão dos valores apurados com a venda de animais, em leite, e calculou o custo operacional total do "leite virtual", que foi de $\mathrm{R} \$ 0,28$. Assim, quando se considerou a venda de animais, a atividade foi rentável em $\mathrm{R} \$ 0,10$ por $\mathrm{kg}$ de leite $(0,38-0,28)$. $\mathrm{O}$ resultado desta pesquisa mostra que, em algumas situações, pode ser verdadeira a afirmação feita por muitos produtores de leite: "produzir leite é mau negócio. O que é bom negócio são as crias. As crias, sim, valem a pena”. Os dados desta pesquisa, que apontam margem líquida positiva (Tab. 2), mesmo sendo o custo operacional total superior ao preço de venda (Tab. 6), confirmam a importância e a aplicabilidade da estimativa do "leite virtual".

\section{CONCLUSÕES}

O nível tecnológico influenciou o custo total de produção do leite e a lucratividade e rentabilidade, sendo os sistemas de produção com nível tecnológico médio e alto insustentáveis. O "peso" dos itens componentes do custo operacional efetivo da atividade leiteira são influenciados pelo nível tecnológico da exploração. A margem líquida positiva e o "resultado" negativo nos três níveis tecnológicos indicam que os pecuaristas estarão se descapitalizando a longo prazo.

\section{REFERÊNCIAS BIBLIOGRÁFICAS}

ALMEIDA JUNIOR, G.A.; LOPES, M.A.; PINATTO, F. Efeito da venda de animais na rentabilidade de um sistema intensivo de produção de leite tipo B no estado de São Paulo In: REUNIÃO ANUAL DA SOCIEDADE
BRASILEIRA DE ZOOTECNIA, 39., 2002, Recife. Anais... Recife: SBZ, 2002. (CD-ROM).

BERG, H.V.D.; KATSMAN, T. Custos comparando despesas na produção do leite. Bol. Leite, v.5, p.3, 1998.

DIAGNÓSTICO da pecuária leiteira do estado de Minas Gerais. Belo Horizonte: SEBRAE/FAEMG, 1996. 102p.

ESTEVES, S.N.; CAMARGO, A.C.; MANSANO, A. et al. Efeitos de tecnologias agropecuárias em estabelecimentos familiares com produção de leite na região de Muriaé/MG. II. Rentabilidade econômica da produção de leite. Muriaé/MG, 2002. (CD-ROM).

GOMES, A.P.; ALVES, E. Identificando ineficiências na produção de leite. Bol. Leite, v.6, p.1-2, 1999.

GOMES, S.T. Indicadores de eficiência técnica e econômica na produção de leite. São Paulo: FAESP, 1997. 178p.

HOLANDA JÚNIOR, E.V.; MADALENA, F.E. Leite caro não compensa. Cad. Téc. Esc.Vet. UFMG, n.25, p.13-18, 1998.

JARRET, J. Produção de leite de qualidade. In: SIMPÓSIO INTERNACIONAL SOBRE PRODUÇÃO INTENSIVA DE LEITE, 3., 1997, Belo Horizonte. Anais... Belo Horizonte: FMVZ, 1997. p.34-45.

LOPES, M.A. Informática aplicada à bovinocultura. Jaboticabal: FUNEP, 1997. 82p.

LOPES, M.A. Sistemas computacionais para cálculo do custo de produção do leite e carne. Lavras: FAEPE/PROEX, 2003. 35p. (Apostila do curso gestão na pecuária de leite e corte: custo de produção, análise de rentabilidade e dimensionamento de rebanhos).

LOPES, M.A.; ALMEIDA JUNIOR, G.A.; CARVALHO, F.C. et al. Estudo da rentabilidade de um sistema de produção de leite tipo B no estado de São Paulo. In: CONGRESSO BRASILEIRO DE ADMINISTRAÇÃO RURAL, 4., 2001, Goiânia. Anais... Goiânia: ABAR, 2001. (CD-ROM).

LOPES, M.A.; CAMPELLO, R.P.; CARVALHO, F.M. et al. Custo Bovino Leite 1.0: software de controle de custos para a atividade leiteira. Rev. Bras. Agroinf., v.4, p.102$115,2002$. 
LOPES, M.A.; CARVALHO, F. M. Custo de produção do leite. Lavras: UFLA, 2000. 42p. (Boletim Agropecuário, 32).

LOPES, M.A.; LOPES, D. C.F. Desenvolvimento de um sistema computacional para cálculo do custo de produção do leite. Rev. Bras. Agroinf., v.2, p.1-12, 1999.

MADALENA, F.E. A vaca econômica. In: ENCONTRO DE PRODUTORES DE F1 JORNADA TÉCNICA SOBRE UTILIZAÇÃO DE F1 PARA PRODUÇÃO DE LEITE, 3., 2001, Juiz de Fora. Anais... Juiz de Fora: Embrapa - CNPGL, 2001. p.9-16.

MARQUES, V.M. Custos e escala na pecuária leiteira: estudo de casos. 1999. 59f. Dissertação (Mestrado em Administração Rural) Universidade Federal de Lavras, Lavras, MG.

MATSUNAGA, M.; BEMELMANS, P.F.; TOLEDO, P.E.N. et al. Metodologia de custo de produção utilizado pelo IEA. Agric. São Paulo, v.23, p.123-139, 1976.
PRADO, E.; CRUZ, F.E.R.; VIANNA, F.C. et al. Avaliação de desempenho técnico econômico de explorações leiteiras em Divinópolis - MG, segundo a forma de produção. Arq. Bras. Med. Vet. Zootec., v.47, p.361-372, 1995.

PREÇO por litro de leite "C" ao produtor e ao consumidor (MG). Disponível em: $<$ http://www.cnpgl.embrapa.br/indicadores/leitec pp.php>. Acessado em: 28 out. 2003.

REIS, R.P. Como calcular o custo de produção. Lavras: Bioex-café, 1999a. 15p. (Informativo Técnico do Café, n.3).

REIS, R.P. Introdução à teoria econômica. Lavras: UFLA/FAEPE, 1999b. 108p.

SCHIFFLER, E.A.; MÂNCIO, A.B.; GOMES, S.T. et al. Efeito da escala de produção nos resultados de produção de leite $\mathrm{B}$ no estado de São Paulo. Rev. Bras. Zootec., v.28, p.425-431, 1999. 